
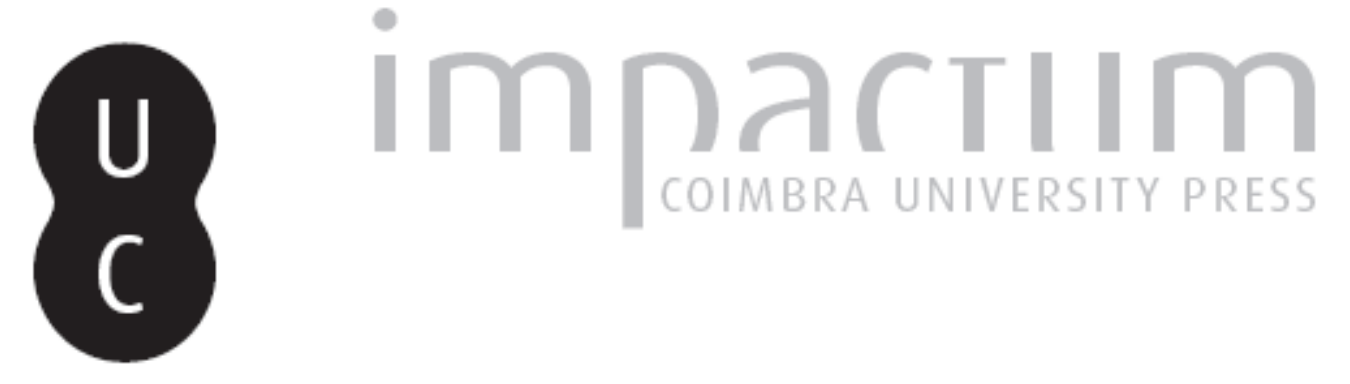

\title{
As bases da indagação darwiniana pelo Homem
}

Autor(es): $\quad$ Regner, Anna Carolina K. P.

Publicado por: CIAS - Centro de Investigação em Antropologia e Saúde

URL persistente:

URI:http://hdl.handle.net/10316.2/28630

DOI:

DOI:http://dx.doi.org/10.14195/2182-7982_27_4

Accessed : $\quad$ 26-Apr-2023 14:02:50

A navegação consulta e descarregamento dos títulos inseridos nas Bibliotecas Digitais UC Digitalis, UC Pombalina e UC Impactum, pressupõem a aceitação plena e sem reservas dos Termos e Condições de Uso destas Bibliotecas Digitais, disponíveis em https://digitalis.uc.pt/pt-pt/termos.

Conforme exposto nos referidos Termos e Condições de Uso, o descarregamento de títulos de acesso restrito requer uma licença válida de autorização devendo o utilizador aceder ao(s) documento(s) a partir de um endereço de IP da instituição detentora da supramencionada licença.

Ao utilizador é apenas permitido o descarregamento para uso pessoal, pelo que o emprego do(s) título(s) descarregado(s) para outro fim, designadamente comercial, carece de autorização do respetivo autor ou editor da obra.

Na medida em que todas as obras da UC Digitalis se encontram protegidas pelo Código do Direito de Autor e Direitos Conexos e demais legislação aplicável, toda a cópia, parcial ou total, deste documento, nos casos em que é legalmente admitida, deverá conter ou fazer-se acompanhar por este aviso.

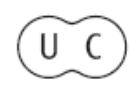




\section{Antropologia Portuguesa}

Volume $26-27 \cdot 2009-2010$

Departamento de Antropologia | Universidade de Coimbra

DARWINISMO:

revisitações, propostas, problemas 


\title{
As bases da indagação darwiniana pelo Homem
}

\author{
Anna Carolina K. P. Regner
}

Universidade do Vale do Rio dos Sinos (UNISINOS), Brasil

aregner@portoweb.om.br

Resumo Desde cedo Charles Darwin incursionou sobre o homem, embora the tenha feito muito breve referência em sua obra magna, A Origem das Espécies, e só o tenha propriamente retomado em The Descent of Man (1871) e em The Expression of the Emotions in Man and Animals (1872). No entanto, já em seus Notebooks M e N de 1838 e 1839, Darwin toma ao homem como objeto de profunda indagação. E como aconteceu com os demais temas da agenda darwiniana ao longo de sua trajetória, os Notebooks de 1836-1844 (especialmente de 1837 a 1839) traçaram o programa de pesquisa a que dedicaria sua vida. Neste artigo pretendo mostrar não só que a visão darwiniana do homem é consistente com sua grande teoria da evolução, esteve lá desde seus primeiros passos e não está comprometida com o que veio depois se chamar de "darwinismo social", onde a imposição de um grupo social sobre outro estaria justificada pelo 'princípio da sobrevivência do mais apto'.

Palavras-chave Charles Darwin; evolução; mente-corpo; natureza humana; seleção natural.

Abstract Since very early, Charles Darwin was deeply involved with the question about man, although he has done a very brief reference to this subject matter in his great work, the Origin of Species (1859 and following editions). Only later Darwin focused on man in The Descent of Man (1871) and in The Expression of the Emotions in Man and Animals (1872). Nevertheless, most of the basic ideas of his theory on man were already outlined in his Notebooks $M$ and $N$ (1838 and 1839). As it also happened with the investigation of the other Darwinian themes, his Notebooks, 1836-1844 (especially those from 1837 to 1839) established the research program to which Darwin would dedicate his life. In this article I intend to show not only that the Darwinian man's vision is consistent with Darwin's great theory of evolution, whose main points were already presented in his Notebooks, but also that since its first steps his theory on man it was not committed with what became called "social Darwinism", in the light of which if one social group takes over another one, it would be just justified by 'the survival of the fittest'.

Key words Charles Darwin; evolution; mind-body; human nature; natural selection. 
Para Darwin, não só fisicamente, mas mental e espiritualmente, o homem é um produto da evolução dos seres vivos. Desde o ponto de vista de sua constituição material, física, biológica, a condição do homem como produto evolutivo enfrentou sérias e bem conhecidas objeções, como a do Bispo Wilberforce, a quem respondeu Thomas Huxley e cujo episódio passou a ser um dos mais citados pela história da ciência (Meeting of the British Association, Oxford, 30 de junho de 1860). Contudo, nada foi maior do que o impacto causado pela explicação da origem da mente humana e suas implicações religiosas. Mesmo Alfred R. Wallace, o célebre companheiro de Darwin na apresentação conjunta de seus papers sobre a seleção natural à Linnean Society em junho de 1858, registra em sua autobiografia quatro pontos de divergência entre ele e Darwin, sendo a primeira relacionada ao homem: para Darwin, a seleção natural explicaria o desenvolvimento físico e mental, enquanto Wallace acreditava que alguma outra agência "análoga à que primeiro produziu a vida orgânica tivesse criado suas faculdade morais e intelectuais" (Wallace, 1871: 236). Para Darwin, a mente humana evoluiu daquela dos animais mais inferiores. Darwin explica o surgimento das capacidades mentais superiores como a linguagem e o pensamento abstrato a partir de capacidades mais simples. De modo similar, nossos sentimentos mais elevados, como os religiosos, teriam gradualmente evolvido de sentimentos encontrados em animais inferiores.

Se pensarmos em mente em termos das capacidades ditas mentais, Darwin também a atribui mesmo aos animais inferiores. Em A Origem das Espécies, cita Pierre Huber: "A little dose of judgment or reason, as Pierre Huber expresses it, often comes into play, even with animals low in the scale of nature" (Darwin 1872: 205)․․ Em síntese, Darwin diferencia o homem de seus pares animais antes por grau do que por natureza: pela conjugação de poderes intelectuais encontrados no homem e por um sentimento de simpatia, ambos fatores sendo nele mais desenvolvidos e resultando no surgimento de uma consciência ética. $\mathrm{O}$ intelecto por si mesmo não seria a principal distinção entre o homem e outros animais. "O hábito pode levar o nosso intelecto a agir erroneamente" (Darwin, 1987: 535 - Notebook M, nota 63). O intelecto é visto como uma modificação do instinto:

1 "Uma pequena dose de juízo ou razão, como Pierre Huber assim o expressa, freqüentemente entra em jogo, mesmo com os animais inferiores na escala da natureza" (Darwin 1872: 205). [A presente e as demais traduções, são traduções livres da A.) 
"Instinct is a modification of bodily structure ... and intellect is a modification of instinct - an unfolding and generalizing of the means by which an instinct is transmitted" (Darwin 1987: 576 - Notebook N, nota 48) ${ }^{2}$.

Bem mais tarde, em The Descent of Man (1871), Darwin vê essa mesma inter-relação entre instinto e livre arbítrio, antes que sua oposição:

"... the more complex instincts seem to have originated independently of intelligence. I am, however, far from wishing to deny that instinctive actions may lose their fixed and untaught character, and be replaced by others performed by the aid of the free will. On the other hand, some intelligent actions (...) after being performed during many generations become converted into instincts and are inherited (...) they are no longer performed through reason or from experience" (Darwin 1981: 37-38) ${ }^{3}$.

No seu Notebook N, na nota 19, Darwin diz: "It is an argument for materialism. that cold water brings on suddenly in head a frame of mind analogous to those feelings which may be considered as truly spiritual" (Darwin 1987: 524) ${ }^{4}$. Nas entradas 1, 2 e 3 do mesmo caderno, Darwin compara a consciência humana e animal. Comentando sobre o comportamento do cão diante de motivos conflitantes (como quando, ao obedecer a seu instinto de correr atrás de uma lebre, é detido pelas moscas, ou por uma tentação maior tal como uma fêmea ou a defesa de seus companheiros), diz que, no caso de possuir algo similar à mente humana, cabe admitir que o cão também compare suas impressões e, se encontrasse que havia desobedecido a um desejo que fosse parte integrante de seu sistema em prol de um passageiro,

${ }^{2}$ Instinto é uma modificação da estrutura corpórea ... e o intelecto é uma modificação do instinto - um desdobramento e generalização dos meios pelos quais um instinto é transmitido (Darwin 1987: 576 - Notebook N, nota 48).

${ }^{3}$... os instintos mais complexos parecem ter sido originados independentemente da inteligência. Contudo, estou longe de querer negar que as ações instintivas possam perder sua fixidez e seu caráter de não aprendidas e possam ser substituídas por outras desempenhadas com o auxílio da vontade livre. Por outro lado, algumas ações inteligentes (...) depois de serem desempenhadas durante muitas gerações convertem-se em instintos e são herdadas (...), não são mais desempenhadas por meio da razão ou da experiência (Darwin 1981: 37-38).

${ }^{4}$ Isto é um argumento a favor do materialismo. que a água fria traga repentinamente à cabeça um estado mental análogo aos dos sentimentos que podem ser considerados como verdadeiramente espirituais. 
teria problema de consciência! Uma idéia que Darwin considera central à sua teoria é a de que se razão for atribuída a qualquer animal com instinto sexual e social, ele deve ter consciência. A diferença entre a consciência do homem e a do cão está em seus instintos originalmente diferentes e no fato de que o homem raciocina muito sobre suas ações e que isso torna sua consciência muito mais sensitiva. No caso do homem, diferentes nações podem ter um senso moral diferenciado, o qual varia a bem de se adaptar a diferentes circunstâncias. O senso moral, contudo, é universal e será adiante explicado como fruto do processo evolutivo. Na nota 4 do Notebook $N$, Darwin aplica seu raciocínio comparativo para explicar a idéia de Deus como um instinto da consciência de um ser humano que sente no seu coração as regras que ele quer transmitir a seus filhos (Darwin, 1987: 564).

Com esse breve intróito, destacamos as seguintes questões que o tema em pauta nos sugere tratar: a visão darwiniana sobre o homem é materialista? É determinista? É empirista? É ateísta? Aponta a uma distinção 'ética'? Como situar o homem no eixo natureza/biologia-cultura/sociedade?

\section{É uma visão materialista?}

Sim e não. A visão darwiniana do homem é materialista no sentido de que as atividades mentais como o pensar são comparadas à realização de um esforço físico e os pensamentos são vistos como prováveis funções da mesma parte do cérebro que afeta a associação das lembranças intencionais de qualquer coisa, "ou a tendência do hábito a produzir um curso de pensamento" (Notebook $M$, notas 46, 61, 62). Uma ação mental é um evento cerebral e pode ser uma causa material de algum outro evento: "One is tempted to believe phrenologists are right about habitual exercise of the mind, altering form of the head, \& thus the qualities becoming hereditary" (Notebook $M$, nota 30$)^{5}$. Na nota 57 , ele adverte a si mesmo:

"To avoid stating how far I believe in Materialism, say only that emotions, instincts, degrees of talent which are hereditary are so because brain of child

${ }^{5}$ É-se tentado a crer que os frenologistas estão certos sobre o habitual exercício da mente alterando a forma da cabeça e então tornando as qualidades hereditárias (Notebook $M$, nota 30 ). 
resemble, parent stock. - (\& phrenologists state that brain alters)" (Darwin 1987: 533$)^{6}$.

Essa última nota parece indicar que o materialismo de Darwin seria dos mais radicais. No entanto, essa posição é, no mínimo, controversa. 'Materialista', à época de Darwin, tinha várias conotações, que davam lugar a complexas e confusas emoções que se mesclavam a forças sociais e culturais conflitantes. Seguindo a tipologia proposta por Maurice Mandelbaum, Edward Manier (1978: 56-57) lista quatro sentidos de 'materialista': (1) aquele que se afasta das visões ortodoxas de Deus e das relações de Deus com a Natureza; (2) aquele que sustenta que a atividade mental ou pensamento é uma função de órgãos corporais, usualmente do cérebro. De acordo com John Stuart Mill, lembra Manier, essa era a definição de materialista aceita então; (3) uma posição que aceita haver um mundo que existe independentemente, que os seres humanos são entidades materiais como qualquer outra, que a mente humana não existe como uma entidade distinta do corpo humano e que não há Deus (nem qualquer outro ser nãohumano) que não seja uma entidade material, e (4) o compromisso com um reducionismo de acordo com o qual não apenas inexistem entidades que não sejam materiais, mas todas as formas ou propriedades do comportamento de objetos materiais particulares são ao fim explicáveis por leis gerais que igualmente se aplicam a todas as manifestações da matéria.

Darwin certamente preenche as duas primeiras condições para ser chamado de materialista. A citação acima revela sua preocupação com a origem corpórea das atividades mentais. Em relação à terceira caracterização, seu 'materialismo' não o teria levado tão longe. Não podemos tomar sem mais como falso seu depoimento dado em carta de 7 de maio de 1879 a John Fordyce, um escritor sobre ceticismo e ciência moderna:

"It seems to me absurd to doubt that a man may be an ardent Theist \& an evolutionist.- You are right about Kingsley. Asa Gray, the eminent botanist, is another case in point-What my own views may be is a question of no consequence to any one except myself.- But as you ask, I may state that my judgment often fluctuates. Moreover whether a man deserves to be called a

${ }^{6}$ Para evitar declarar o quanto eu creio no materialismo, dizer apenas que as emoções, instintos, graus de talento os quais são hereditários, o são porque o cérebro da criança é semelhante ao do estoque parental - (e os frenologistas afirmam que o cérebro se altera). 
theist depends on the definition of the term: which is much too large a subject for a note. In my most extreme fluctuations I have never been an atheist in the sense of denying the existence of a God.-I think that generally ( $\&$ more and more so as I grow older) but not always, that an agnostic would be the most correct description of my state of mind." (Darwin Correspondence Projectletter 12041. [Consultado em 29/01/2010]. http://www.darwinproject.ac.uk/ content/blogcategory/36/63//7.

Sua visão de Natureza, por sua vez, parece afastá-lo do reducionismo presente na quarta caracterização acima de 'materialismo'. A natureza, segundo Darwin, tem as suas próprias leis gerais, mas que não se reduzem às da Física e da Química. Em A Origem, ele diz:

"Throw up a handful of feathers, and all fall to the ground according to definite laws; but how simple is the problem where each shall fall compared to that of the action and reaction of the innumerable plants and animals which have determined, in the course of centuries, the proportional numbers and kinds of trees now growing on the old Indian ruins!" (Darwin, 1872: 58) ${ }^{8}$.

Em qualquer caso, porém, o lado mais atraente da questão acima sobre o "materialismo" seria o de levar a um abandono de nossa arrogância ou auto-admiração como criaturas especiais neste mundo. Ao abandonar tal prerrogativa, também nos tornávamos explicáveis como seres 'naturais'. Estávamos por certo inseridos no curso da evolução.

${ }^{7}$ Parece-me absurdo duvidar de que um homem possa ser um ardente teísta e um evolucionista. - Você está certo sobre Kingsley. Asa Gray, o eminente botânico, é outro caso a esse respeito. - O que minhas próprias idéias possam ser é uma questão sem conseqüência para qualquer um que não eu mesmo. - Mas, como você me pergunta, posso declarar que meu julgamento freqüentemente flutua. Além disso, se um homem merece ser chamado de teísta depende da definição do termo: tema que é muito amplo para uma nota. Em minhas mais extremas flutuações nunca fui um ateu no sentido de negar a existência de Deus. - Penso que, em geral (e mais e mais na medida em que fico mais velho), mas não sempre, agnóstico seria a descrição mais correta do meu estado de espírito (Darwin Correspondence Projecthttp://www.darwinproject.ac.uk/content/blogcategory/36/63/ - letter 12041).

${ }^{8}$ Atire uma mão cheia de penas, e todas cairão ao solo de acordo com leis definidas; mas quão simples é o problema de saber onde cada uma cairá comparado ao da ação e reação das inumeráveis plantas e animais que determinaram, no curso dos séculos, a proporção entre números e espécies de árvores hoje crescendo nas velhas ruínas indígenas! 


\section{É uma visão determinista da natureza do Homem?}

Como ser 'natural' e fruto do processo evolutivo que perpassa os seres vivos, o homem está submetido às leis da Natureza. Darwin concebia a Natureza como um sistema de leis (vide abaixo) e foi fortemente influenciado pelo conceito de 'leis naturais' de Augusto Comte. Apesar disso, a concepção darwiniana de Natureza tem suas peculiaridades e mantém aquela admiração frente a Natureza que encontrou em Personal Narrative de Alexandre Humboldt, uma das duas obras que mais o influenciaram, segundo seu depoimento autobiográfico ${ }^{9}$. A Natureza foi concebida por Darwin como um sistema de leis no início do capítulo IV e, dois parágrafos adiante, como um ser autônomo: logo, como um sistema autônomo, operando por suas próprias leis (em seu Ensaio de 1844 refere-se a um "Ser sagaz"), deixando de lado "o mistério do começo de todas as coisas" como um problema insolúvel para a mente humana. Trata-se de uma visão de Natureza capturada em linguagem metafórica, 'personalizada', tanto no sentido mecanicista de um sistema de leis, como no teleológico de um sujeito que age autonomamente:

"... it is difficult to avoid personifying the word Nature; but I mean by Nature, only the aggregate action and product of many natural laws, and by laws the sequence of events as ascertained by us." (Darwin, 1872: 63).

"Nature, if I may be allowed to personify the natural preservation or survival of the fittest, cares nothing for appearances, except in so far as they are useful to any being. She can act on every internal organ, on every shade of constitutional difference, on the whole machinery of life. Man selects only for his own good: Nature only for that of the being which she tends." (Darwin, 1872: 65$)^{10}$.

${ }^{9}$ Segundo Manier (1978: 186) esta visão de Natureza é uma mistura das crenças de Dugald Stewart em sinais naturais na Natureza, sendo essa expressiva, e da leitura que John Fleming faz dos traços e emoções humanas em termos não-Cartesianos, bem como da rejeição por parte de Lamarck e de outros zoólogos da definição cartesiana da matéria como sendo inerte. Se Hume e Comte proibiram Darwin de explicitar suas idéias dentro de teísmo bem articulado, a visão poética do The Excursion de Woodsworth (que acompanhou Darwin por sua vida) o dirigiu para uma solução não-ateísta para seus questionamentos sobre acaso e sofrimento, esperança e amor, colocando a busca do sentido da vida na Natureza mesma.

${ }^{10}$... é difícil evitar de personificar a palavra Natureza; mas por Natureza tenho em mente apenas a ação agregada e o produto de muitas leis naturais e por leis a seqüência dos eventos tais como verificados por nós (Darwin, 1872: 63). 
Muitas leis darwinianas (Darwin, 1872: capítulo V) estão bem distantes das leis básicas da Física e da Química. A Natureza concebida por Darwin como um sistema auto-regulado não excluiu a teleologia ou explicações em termos de propósitos e também não o comprometeu com o conceito de um Planificador supranatural a bem de explicar os fenômenos naturais. Em uma carta a Asa Gray de 04 de junho de 1874, Darwin agradece-lhe por seu artigo sobre as idéias de Darwin, publicado em Nature no dia anterior (Gray, Asa. 1874. Notice [of Charles Robert Darwin] by Asa Gray. The American Naturalist 8, No. 8. (August): 475-479. [Consultado em 29/01/2010] http:// darwin-nline.org.uk/supplementary_works.html\#otherancillary).

Darwin explicitamente admite a teleologia como definida por Asa Gray em seu artigo, isto é, em termos 'naturais'. Gray refere-se ao grande serviço que Darwin prestou à ciência natural ao trazer-lhe de volta a teleologia, de modo que, ao invés de opor a Morfologia à Teleologia, deveríamos ter a Morfologia unida à Teleologia. É também nesses termos que Huxley adota uma posição similar no capítulo "On the Reception of the 'Origin of Species"" que escreveu a pedido para a edição de Life and Letters of Charles Darwin preparada por Francis Darwin em 1888. A peculiar legalidade da Natureza darwiniana permitia-lhe dar conta de fenômenos naturais também em termos de suas 'disposições internas', 'funções' e 'propósitos' (essa última expressão aparece constantemente em boa parte de suas explicações).

Interessa-nos aqui, em particular, as questões relacionadas a 'necessidade versus livre arbítrio', uma vez que, tradicionalmente, "necessidade" é associada a causa material e "livre arbítrio" a escolha meditada tendo em vista os fins a alcançar. Para o embate "necessidade versus explicações em termos de propósitos, fins e funções', Darwin encontrou solução em sua visão de Natureza dotada de uma legalidade própria com espaço para uma finalidade imanente ao próprio sistema. $\mathrm{O}$ mesmo não ocorre com o embate 'necessidade versus desígnio', refletindo-se esse embate sobre "desígnio" na questão do livre arbítrio, por ambos envolverem a questão difícil de um princípio de finalidade.

Natureza, se me for permitido personificar a preservação natural ou a sobrevivência do mais apto, não se preocupa com as aparências, exceto se úteis a um ser qualquer. Ela pode agir sobre todo o órgão interno, sobre toda sombra de diferença de constituição, sobre a inteira maquinaria da vida. $\mathrm{O}$ homem age apenas para o seu próprio bem; a Natureza para o bem do ser de que cuida (Darwin, 1872: 65). 
Ao se referir a suas próprias opiniões sobre 'livre arbítrio', respondendo a cartas em que era perguntado sobre tais assuntos ${ }^{11}$, Darwin respondia que não era um expert e deixava ver sua profunda perplexidade sobre o tema. Não o considerava um 'dom especial' com que o homem fora agraciado por Deus. Antes, relacionava sua perplexidade ao argumento do sofrimento no mundo contra a existência de um Deus que, sendo onisciente, deveria ser benevolente. Todavia, não podia igualmente conceber, como o referiu em mais de uma carta, que este mundo ordenado fosse fruto do mero acaso. Desde um ponto de vista cosmológico, encontrava um argumento (o único) a favor da existência de Deus. Assim como o conflito entre ambos os argumentos, ético e cosmológico, parecia-lhe além da mente humana, também assim lhe parecia o conflito entre necessidade e livre arbítrio. Darwin não resolve plenamente o conflito entre a necessidade das leis a que se encontra submetido o homem como ser natural e a suposta independência que o livre arbítrio the atribui. Sua perplexidade deixa-nos ver a complexidade da questão, sem abrir mão da visão da mente como uma função de órgãos corporais.

A respeito do livre arbítrio, os pensamentos iniciais de Darwin encontram-se no seu Notebooks $M$ (de 15 de julho a 02 de outubro de 1838) e $N$ (de 02 de outubro de 1838 à metade de 1839). Um de seus argumentos baseia-se na condição de 'causalidade'. Segundo Darwin, nenhum animal hoje existente pode ter sido causa de si mesmo e vê nisso uma grande probabilidade contra a ação livre, concluindo que "on my view of free will, no one could discover he had not it" (Darwin, 1987: 576-577) 12. Podemos nos experienciar como agentes causais possuindo livre arbítrio, mas, de acordo com a fixidez das leis naturais de Comte - diz Darwin nas notas 69, 70 e 72 do Notebook $M$ - podemos suspeitar que mesmo a vontade surja segundo 'lei fixas' de organização e que "livre arbitrio seja para a mente o que o acaso seja para a matéria" (Darwin, 1987: 535, 536). Se pudéssemos colocar-nos fora de nós mesmos, veríamos como nossa vontade pode ser determinada por leis naturais. Comentando uma palestra do Reverendo Algernon Wells sobre instinto animal, cuja perfeição seria uma prova do desígnio de Deus na Natureza (Notebook $N$, nota 68-9), Darwin nega ser "inteiramente verdadeiro" que a realização de atos instintivos seja desprovida de qualquer

\footnotetext{
${ }^{11}$ Como exemplo, vide sua carta resposta a Mary Boole (viúva do famoso matemático), de 14 de dezembro de 1866 (Darwin, 2004, vol. 14: 425-426).

12 “- em minha visão do livre arbítrio, ninguém poderia descobrir que não o tivesse." (Darwin 1987: 576-577).
} 
intencionalidade do sujeito. Na nota 77, ele alega que "instinct is hereditary knowledge of things which might be possibly acquired by habit" (Darwin 1987: 585$)^{13}$.

Todavia, a questão do livre arbítrio e sua possibilidade de interferência no curso natural dos eventos não nos parece até aqui uma questão plenamente resolvida. Darwin continua falando, de um lado, que ações instintivas podem perder seu caráter fixo e serem substituídas por outras com o auxílio do livre arbítrio (Darwin 1981: 37-38). De outro, pode-se pensar que, se a mente tem uma estrutura corpórea e como tudo o mais está sujeita a leis naturais, e se o livre arbítrio é mero acaso; uma vez que aquilo resulta do acaso não pode ser racionalmente determinado, deveria o fenômeno do 'livre arbítrio' ser omitido do âmbito das explicações racionais? Talvez a solução darwiniana a esse problema seja aquela expressa em algumas de suas cartas, como no 'em tempo' que escreveu na carta que enviou a Charles Lyell em 15 de Abril de 1860, onde diz que a questão do desígnio de uma divindade onisciente e onipotente, bem como a da predestinação e livre arbítrio ou a da origem do mal, estão além do intelecto humano (Darwin, 1993: 161). Posições similares adota em carta a Asa Gray de 22 de maio de 1860 e a William Graham em julho de 1881.

\section{É uma visão empirista?}

A visão darwiniana do homem foi fortemente influenciada pelo empirismo $^{14}$. Na explicação empirista de Darwin do pensar, da formação das idéias abstratas, de nossa idéia de Deus e do papel desempenhado pelo hábito em nossas operações mentais a presença da teoria Humeana das idéias como cópias das impressões e o papel do hábito na formação das crenças, no desempenho das capacidades humanas e na visão da razão humana como um instinto, pode ser encontrada no Notebook $M$, notas 101,104 e 155 (Darwin, 1987: 545 e 559) ${ }^{15}$. A repetição transforma um ato voluntário em

13 “instinto é o conhecimento hereditário das coisas que possivelmente poderiam ter sido adquiridas por hábito" (Darwin 1987: 585).

${ }^{14}$ Uma excelente análise da rede de influências que o jovem Darwin sofreu, o Darwin do período em que redigia seus Notebooks, é oferecida por Manier (1978).

${ }^{15}$ O Notebook $C$ de Darwin, em sua nota 267, contém listas de leituras a realizar entre as quais está incluída a leitura de Essay on Human Understanding. A essas listas, foi acrescentada uma nota posteriormente (nota 276-1), dizendo que essas leituras haviam sido 
involuntário. Assim, não só mudanças em geral, mas pensamentos tornamse habituais.

Darwin mantinha, contudo, uma atitude crítica em relação a Hume. Discordava da extrema importância atribuída aos sentidos e ao papel de idéias inconscientes nas operações mentais (Notebook $M$, notas 104 e 105). Lembremos a ação do hábito sobre a mente gerando a impressão de necessidade, origem, segundo Hume, da idéia de conexão necessária atribuída à relação causal. A origem da idéia de 'causa' era de particular interesse para Darwin. Segundo ele, algumas idéias, como a de 'causa', não podem ser explicadas apenas por impressões externas, nem podem ser anuladas em seu uso metafísico, como no caso da conexão da idéia de causa com a de Deus. Muitos anos mais tarde, em uma carta a N. D. Doedes de 02 de abril de 1873, Darwin refere-se a essa conexão, ressaltando que a conclusão mais segura está além do intelecto humano:

"I may say that the impossibility of conceiving that this grand and wondrous universe, with our conscious selves, arose through chance, seems to me the chief argument for the existence of God; but whether this is an argument of real value, I have never been able to decide. I am aware that if we admit a first cause, the mind still craves to know whence it came and how it arose. Nor can I overlook the difficulty from the immense amount of suffering through the world. I am, also, induced to defer to a certain extent to the judgment of the many able men who have fully believed in God; but here again I see how poor an argument this is. The safest conclusion seems to be that the whole subject is beyond the scope of man's intellect; but man can do his duty" (Darwin Correspondence Project - letter 8837 [Consultado em 29/01/2010]. http://www.darwinproject.ac.uk/nota-8837) ${ }^{16}$.

realizadas (Darwin 1887: 320, 323). Notebook M, como apontado por Paul Barret, traz a marca 'privado' na sua folha de rosto interna; nesse caderno, há observações de qualidades mentais normais e anormais de Darwin, sua família e seus amigos (Darwin 1987: 517).

${ }^{16}$ Posso dizer que a impossibilidade de conceber que este grande e maravilhoso universo com nossas próprias consciências surgiu do acaso parece-me ser o argumento chave para a existência de Deus; mas se este é um argumento de real valor, nunca fui capaz de decidir. Estou consciente de que, se admitimos uma primeira causa, a mente ainda anseia por saber em que tempo e como surgiu. Nem posso deixar de considerar a dificuldade da imensa quantidade de sofrimento no mundo. Sou também induzido a ceder, em certa medida, ao julgamento de muitos homens capazes que plenamente crêem em Deus; mas aqui também vejo quão pobre um argumento como esse é. A conclusão mais segura parece ser a de que o projeto inteiro 
Comentando em seu Notebook $N$ (nota 60), a propósito do exame da idéia de causalidade feita por John Herschel em seu Discourse, que a mera sucessão de noite e dia não nos dá a noção de causa (Darwin, 1987: 579), Darwin diz que isso não significa que temos algumas idéias necessárias platonicamente pré-existentes na mente. Em termos darwinianos, 'pré-existência' refere-se a "nossos ancestrais". Na nota 128 do Notebook M, Darwin diz:

"Plato ... says in Phaedo that our necessary ideas arise from the preexistence of the soul, are not derivable from experience - read monkeys for pre-existence" (Darwin 1987: 551) ${ }^{17}$.

Em um comentário de 1838 às Provas de John Macculloch e Ilustrações dos Atributos de Deus (1837), Darwin diz:

"I see no reason why structure of brain should not be born, with tendency to make animal perform some action. - as well as gain it. By habit. - New theory of instinct, returning to Kirby's view." (Darwin 1987: 638, nota 59) ${ }^{18}$.

Para ele, a idéia de causalidade é tão forte que, quando não há causa aparente a ser dada, "a pessoa fixa em seres imaginários, muitos vicariantes, como nós mesmos", como os selvagens que consideram trovão e raio como o testamento direto de Deus, relembrando os estágios Comteanos do conhecimento humano.

A origem da idéia de Deus também pode ainda ser relacionada à idéia de um "dever" moral, muito embora, como na resposta da carta a Doedes acima, Darwin reconheça que a questão da existência ou não de Deus não facilita nem impede que cumpramos com nosso dever.

está além do alcance do intelecto humano; mas o homem pode cumprir com o seu dever (Darwin Correspondence Project - letter 8837 -http://www.darwinproject.ac.uk/entry-8837)

${ }^{17}$ Platão diz no Fédon que nossas idéias necessárias surgem da pré-existência da alma, não são deriváveis da experiência - leia-se macacos em lugar de pré-existência (Darwin 1987: 551). (Nota da A.: Darwin depois acrescentou 'Erasmus' após Platão, o que pode sugerir ter sido seu irmão Erasmus a fonte da informação sobre Platão).

${ }^{18}$ Eu não vejo nenhuma razão por que a estrutura de cérebro não deveria nascer com tendência para fazer com que um animal execute alguma ação. - bem como para ganhá-la pelo hábito. Nova teoria do instinto, retornando à visão de Kirby (Darwin 1987: 638, nota 59). 


\section{É uma visão ateísta?}

Chegamos agora a um dos pontos mais polêmicos das discussões contemporâneas sobre o Darwinismo. Muitas são as respostas, privilegiando ora um tipo, ora outro de argumento. Acompanhando a trajetória desta questão ao longo do pensamento darwiniano, podemos, no entanto, ver que, sob diferentes versões, 'Deus/Ciência' foi uma controvérsia interna que, com maior ou menor intensidade, acompanhou Darwin ao longo de sua vida ${ }^{19}$. A pertinência em evocá-la aqui, antes que penetrar na discussão do ateísmo ou não de Darwin, busca destacar que sua visão do homem como um ser 'natural', cuja integridade corpo-e-mente é explicável evolutivamente pela seleção natural, não resulta nem de um pretenso ateísmo de Darwin, nem de um pretenso teísmo. Assim como sua grande teoria da seleção natural, a avaliação dos méritos ou deméritos de sua visão da natureza humana não depende da crença ou não na existência de um Criador, nem provê a essa evidência corroboradora ou falseadora. Essa é uma avaliação que depende de uma rede complexa de vários fatores.

Darwin nunca tratou em suas publicações de questões teológicas ou religiosas. Sua correspondência e sua autobiografia estão, contudo, repletas de passagens a respeito. Apesar de na sua autobiografia criticar a idéia de Revelação bíblica, nela se declara teísta ao tempo em que escreveu a Origem das Espécies, em 1859. Embora tenha revisado e feito alterações em todas as edições da obra, exceto a segunda, nunca alterou o tom teísta que traz em seu último parágrafo, assim persistindo até 1872, e o qual já pode ser encontrado em seu Notebook de 1837. Darwin tentou manter ciência à parte da religião, embora, como vimos acima na carta a Fordyce, explicitamente admita a compatibilidade de sua teoria evolucionista com teísmo. Em carta escrita a F. E. Abbot em 6 de setembro de 1871, um clérigo americano que defendia a liberdade de pensamento e 'verdadeira religião' e com quem Darwin se correspondeu regularmente desde 1871, Darwin responde ao pedido de Abbot para enviar uma nota à apresentação da compatibilidade da teoria de Darwin com sentimentos religiosos em uma conferência a ser ministrada por Abbot, declinando de enviar a solicitada nota e abstendo-se de comentar sobre tal compatibilidade, alegando que suas próprias visões não eram claras

19 "Deus e a Ciência: a controvérsia interna de Darwin" foi tema detidamente analisado pela Autora em conferência apresentada no IX Simpósio Internacional IHU: Ecos de Darwin, 4 a 9 de setembro de 2009, Universidade do Vale do Rio dos Sinos, São Leopoldo, Brasil. 
e que nunca havia podido decidir até que ponto a convicção interna de que deve haver algum Criador ou Causa Primeira seria realmente uma evidência confiável. Às razões acima, Darwin acresce que se sentia em certa medida sem vontade de expressar-se publicamente sobre matérias religiosas por não haver pensado sobre tais questões com profundidade suficiente para justificar qualquer manifestação pública (Darwin 1888, vol. I: 305-306).

Posteriormente, ante novos pedidos de Abbot e de outros, Darwin recusa-se novamente a escrever sobre ciência e religião e a participar de reuniões para a discussão sobre como ciência e religião poderiam correr harmoniosamente juntas, por não ver nenhum benefício a resultar de tais reuniões, se o tema não fosse tratado em sua devida extensão, e porque, em sua opinião, um homem que desejasse formar um juízo sobre a questão, deveria pesar a evidência e não ser influenciado pelo fato de um número considerável de cientistas poder reconciliar os resultados da ciência com a religião revelada ou natural (Darwin Correspondence Project - cartas 12931, 12930, 12918, 12919, e 12789 [Consultado em 29/01/2010]. http:// www.darwinproject.ac.uk/content/blogcategory/36/63/).

Em que pese a recusa de Darwin em buscar uma (re)conciliação entre ciência e religião, várias foram as tentativas feitas por seus contemporâneos (leitores diversos, clérigos, naturalistas) nessa direção, no que concerne à própria teoria darwiniana e mesmo sobre as crenças pessoais de Darwin sobre questões religiosas. Darwin respondia aos pedidos e perguntas cordialmente mas firmemente, dizendo que não poderia esclarecer suas dúvidas, que a evidência requerida pela ciência era de natureza diferente da conviç̧ão religiosa, que as questões propostas lhe eram muito abstrusas e que não tinha se aprofundado o suficiente nelas para responder. Quando diretamente perguntado sobre suas crenças pessoais, informava que não acreditava na Bíblia como uma revelação divina e que, portanto, não acreditava em Jesus Cristo como o filho de Deus (por exemplo, em Darwin Correspondence Project - carta 12851 [Consultado em 29/01/2010]. http://www.darwinproject.ac.uk/content/blogcategory/36/63/).

Na sua Autobiografia (1876), logo após dizer que merecia ser chamado de teísta à época em que escreveu a Origem (1959), Darwin diz: "O mistério do início de todas as coisas é insolúvel para nós; de minha parte, devo contentar-me com permanecer um Agnóstico" (Darwin 1993a: 93-94). De fato, à luz da convicção de Darwin na origem material da mente humana cujas faculdades e atividades superiores evoluíram desde as mais simples e da sua visão dos limites da mente humana para assuntos abstrusos como livre 
arbítrio versus necessidade, seu agnosticismo, mais de uma vez declarado em suas cartas, é um predicamento razoável.

\section{A differentia proporcionada pela consciência ética}

Talvez Darwin veja no sentido moral a melhor e superior distinção entre o homem e os animais inferiores:

"The moral sense perhaps affords the best and highest distinction between man and the lower animals; but I need not to say anything on this head, as I have so lately endeavoured to shew that social instincts, - the prime principle of man's moral constitution - with the aid of active intellectual powers and the effects of habit, naturally lead to the golden rule, "As ye would that men should do to you, do you to them", and this lies at the foundation of morality" (Darwin, 1981: 106) ${ }^{20}$.

Essa dimensão ética está integrada na visão evolucionista Darwiniana. Conforme registra em sua autobiografia e na carta a Doedes acima transcrita, a realização dessa dimensão não dependia da crença ou não na existência de Deus ou em uma vida futura. Essa dimensão, por sua vez, pode levar a uma recolocação da questão do 'livre arbítrio', bem como encaminhar a uma análise da relação natureza-cultura na determinação do homem. Desde seus Notebooks até The Descent of Man, a seguinte proposição, já referida acima, parecia-lhe altamente provável:

“(...) that any animal whatever, endowed with well-marked social instincts, would inevitably acquire a moral sense or conscience, as soon as its intellectual powers had become as well developed, or nearly as well developed, as in man" (Darwin 1981: 72) ${ }^{21}$.

${ }^{20} \mathrm{O}$ senso moral talvez forneça a melhor e mais alta distinção entre o homem e os animais inferiores; mas não preciso dizer nada sobre o tema, uma vez que há bem pouco esforcei-me por mostrar que os instintos sociais, - o primeiro princípio da constituição moral do homem - com o auxílio dos princípios intelectuais ativos e dos efeitos do hábito, naturalmente levam à regra de ouro: "Trate as pessoas como você gostaria que elas o tratassem", e isso está à base de toda a fundamentação moral (Darwin, 1981: 106).

${ }^{21}$ (...) que qualquer animal, dotado com instintos sociais bem marcados inevitavelmente adquirisse um senso moral ou consciência, assim que seus poderes intelectuais tivessem se tornado bem desenvolvidos, ou quase tão bem desenvolvidos, como no homem (Darwin, 1981: 72). 
Ao que acrescenta, situando o homem no curso 'natural' da evolução:

"Besides love and sympathy, animals exhibit other qualities which in us would be called moral: (...)" (Darwin 1871: 78) 22 .

Essa perspectiva distingue Darwin de outros pensadores, sobretudo empiristas, que colocam nas sensações de prazer e de dor a base última de nossos instintos e sentimentos:

"No one, I presume, can analyse the sensations of pleasure or pain. (...) The common assumption that man must be impelled to every action by experiencing some pleasure and pain may be erroneous" (Darwin 1871: 79-80)23.

Em The Descent of Man, a longa reflexão do seu capítulo III, Moral Sense, retomada no capítulo V, Moral faculties, revela que, à base da moralidade que distingue o homem dos outros animais, encontram-se os instintos sociais, para o bem da comunidade, partilhados por homens e animais inferiores, que levam ao amor e à simpatia pelos demais, ao ensejo de sua aprovação pelos seus companheiros e desta ao sentimento de certo e errado, de onde se origina sua consciência moral, quando o homem torna-se juiz dos seus atos, a parte mais nobre da natureza humana. Aqueles instintos sociais levaram o homem inicialmente ao desejo de ajudar seus companheiros e a um sentimento de simpatia, fornecendo-lhe uma regra grosseira de certo e errado. O hábito de ajudar seus companheiros e realizar ações benevolentes certamente fortalece o sentimento de simpatia. Estímulo ainda mais poderoso é o desejo de aprovação e a repulsa à infâmia, o amor ao reconhecimento do mérito e a repulsa à culpa.

Com o desenvolvimento de suas capacidades intelectuais e de sua instrução pelo hábito seguindo as experiências benéficas, suas simpatias tornaram-se mais ternas e ampliadas a todos os homens de todas as raças, aos incapacitados e aos animais inferiores. A diferença entre a mente do homem e dos animais inferiores é de grau, antes que de natureza. Nessa

${ }^{22}$ Além do amor e simpatia, os animais exibem outras qualidades que, se nossas, chamaríamos de morais (...) (Darwin, 1871: 78).

${ }^{23}$ Ninguém, presumo, pode analisar as sensações de prazer ou dor (...) A suposição comum de que o homem deve ser impelido a toda a ação pela experiência de prazer ou de dor pode estar errada (Darwin, 1871: 79-80). 
diferenciação, o uso da linguagem articulada, característico do homem, teve um papel central, porque propiciou o desenvolvimento de outras faculdades intelectuais avançadas que, por sua vez, levaram a poderes tais como autoconsciência e abstração.

Nas suas considerações conclusivas do capítulo XXI de The descent of man, and selection in relation to sex, Darwin diz:

"The moral nature of man has reached the highest standard as yet attained, partly through the advancement of the reasoning powers and consequently of a just public opinion, but specially through the sympathies being rendered more tender and widely diffused through the effects of habit, example, instruction, and reflection. (...) Ultimately, man no longer accepts praise or blame of his fellows as his chief guide, though few escape this influence, but his habitual convictions controlled by reason afford him the safest rule. His conscience then becomes his supreme judge and monitor. Nevertheless the first foundation or origin of the moral sense lies in the social instincts, including sympathy; and these instincts no doubt were primarily gained, as in the case of the lower animals, through natural selection" (Darwin, 1981: 394) 24. $^{24}$

Aqui podemos recolocar a questão do livre arbítrio, não mais em termos da natureza humana estar ou não sujeita a leis que determinam o curso dos eventos, mas da natureza humana contar com uma consciência crítica, alcançada através da legalidade desse curso, mas que, uma vez alcançada, constitui-se em uma instância arbitral legítima, tornando o homem responsável pelos seus atos, sem para tanto requerer a chancela de um Bem Superior (Deus) ou a promessa de uma vida futura. Podemos também, por uma sociabilidade oriunda dos instintos sociais, os quais compartilhamos com os

\footnotetext{
${ }^{24}$ A natureza moral do homem atingiu o padrão mais alto até aqui obtido, parcialmente pelo desenvolvimento dos poderes de raciocínio e, conseqüentemente, de uma justa opinião pública, mas especialmente por suas simpatias terem se tornado mais ternas e amplamente difundidas pelos efeitos do hábito, exemplo, instrução e reflexão. (...) Ao final, o homem não mais aceita a honra ou a culpa atribuída por seus companheiros como seu guia, embora poucos escapem a essa influência, mas as suas convicções usuais controladas pela razão fornecemlhe a regra mais segura. Sua consciência torna-se então seu supremo juiz e monitor. Apesar disso, a primeira fundação ou origem do senso moral está nos instintos sociais, incluindo a simpatia; e esses instintos, sem dúvida, foram primeiramente ganhos, como no caso dos animais inferiores, por meio da seleção natural (Darwin, 1981: 394).
} 
animais inferiores, e refinada pelo desenvolvimento de nossos sentimentos e capacidades intelectuais, a respeito das quais nos distinguimos dos animais inferiores, compreender o papel que o social e a cultura desempenham na formação de nossa natureza.

\section{O'natural' e o 'cultural': uma via de duas mãos}

O social não é, pois, algo que se agrega ao físico ou biológico. $\mathrm{Na}$ visão darwiniana, somos 'animais sociais' e não, 'animais que se tornaram sociais'. Assim, pertence à nossa natureza a condição de seres sociais, o que significa, em termos darwinianos, estarmos fundados nas relações de simpatia e amor ${ }^{25}$.

Desde sua viagem a bordo do Beagle (1831-1836), ainda que essa o tenha feito reconhecido como 'naturalista', o 'natural' e o 'cultural' revelaram-se vias de mútua penetração no pensamento de Darwin. Suas notas de viagem também se dedicam em boa parte à descrição e análise de fenômenos sociais, culturais e políticos. De seu diário de viagem, colhemos suas análises não apenas de fenômenos naturais, mas da escravidão negra no Brasil, onde aflora seu profundo sentimento anti-escravagista e de respeito pelos negros, da cultura do gaúcho, da condição de vida dos mineiros chilenos, explorados pelos donos das minas, do projeto político de Rosas e do extermínio da civilização indígena na América do Sul, momento em que exalta a independência e altivez do indígena que não é co-optado pelo colonizador e fala com certo desprezo do indígena que se tornou servil.

Em suas descrições faz-se presente um tom moral que, por vezes, deixa claramente entrever um 'viés' inglês nas palavras do jovem liberal (partidário dos Whigs), em parte talvez pelo toque ingênuo de seu entusiástico e 'progressista' nacionalismo. Este é o caso, por exemplo, de suas descrições do papel dos missionários ingleses na Nova Zelândia e no Taiti, ou de sua avaliação da ditadura de Francia no Paraguai. Em uma passagem, regressando pelo rio Paraná, de Santa Fé Bajada a Buenos Aires, em 18 e 19/outubro/1833, diz:

${ }^{25}$ Diferentemente, pois, da visão Malthusiana, segundo a qual o sentimento básico seria o egoísmo. 
"How different would have been the aspect of this river if English colonists had by good fortune first sailed up the Plata! (...)That country will have to learn, like every other South American state that a republic cannot succeed till it contains a certain body of men imbued with the principles of justice and honour." (Darwin, 1962: 140) ${ }^{26}$.

Em que pese a virtual propriedade da advertência contida no último comentário, hoje é bem conhecida a independência econômica do Paraguai de então com relação à Inglaterra, posição única entre as nações sul-americanas àquele tempo.

Atendo-nos ao ponto em questão, a integração do 'natural' e do 'cultural' nas descrições Darwinianas aparecem em diferentes níveis, seja na sua observação da adaptabilidade da língua indígena para dar nome às mais triviais características da terra (Darwin, 1962: 299), seja na sua observação do avanço nas 'artes da civilização' alcançado pelos incas e da integração de suas huascas na paisagem (Darwin, 1962: 399), seja na estratégia que o acompanhará sempre nas suas investigações de buscar evidências interdisciplinares, em que achados paleontológicos, arqueológicos e geológicos mutuamente se sustentam (Darwin, 1962: 370-371). A um nível mais fundamental ainda, encontra-se tal integração relacionada a ingredientes teóricos básicos constitutivos do princípio-chave da Seleção Natural e da visão de Natureza que servirá de suporte a todo o trabalho de Darwin. A esse nível, pode ser detectada a inserção do social, cultural, na elaboração de um instrumental de análise de fenômenos naturais.

Assim, o complexo conceito de 'condições de vida', com seu papel determinante no que concerne a 'mudanças adaptativas, tendo em vista a sobrevivência', aparece nas páginas de seu diário, referindo-se a ambas as dimensões fenomênicas, a 'natural' e a 'cultural'. Aparece, por exemplo, relacionado à força do hábito e dos efeitos hereditários nas adaptações dos fueguinos ao clima e às 'produções de sua miserável região', conforme registro da visita de Darwin em dezembro/1832 (Darwin, 1962: 217; Barlow, 1934: 213). Também aparece em sua inferência acerca da aquisição de comportamento selvagem em relação ao homem por parte de pássaros que

${ }^{26}$ Como seria diferente o aspecto deste rio se colonizadores ingleses tivessem afortunadamente navegado pelo Prata primeiro!(...) Este país terá de aprender, como todos os outros estados sul-americanos, que uma república não pode ser bem sucedida até que possua um certo corpo de homens imbuídos com os princípios da justiça e da honra (Darwin, 1962: 140). 
seriam originariamente dóceis, como os encontrados nas Ilhas Galápagos e Falkland (Darwin, 1962: 401). Esse comportamento adquirido tornarse-ia hereditário - ponto nunca abandonado de vez por Darwin e bastante recorrente em seu diário.

Relacionado a essas suposições, vê-se outro ponto que será central à explicitação posterior do complexo conceito de condições de vida: o de uma 'política da Natureza', regulando seus equilíbrios e desequilíbrios. Em sua obra madura, a Origem das Espécies, prevalecerá a influência de tais relações 'políticas' entre os seres orgânicos sobre a ação direta do clima ou de outros fatores físicos, como fatores determinantes para alterações em vista de quais variações serão favoráveis ou não, preservadas (e acumuladas) ou extintas. Isso sugere o papel determinante das 'relações de poder' para a ação das 'condições de vida', geradora de aperfeiçoamento, diferenciação e complexificação das relações. Tal concepção aparece nos relatos de Darwin referentes às condições de vida dos fueguinos e do gaúcho, sobretudo o guaso do Chile:

"The perfect equality among the individuals composing the Fuegian tribes, must for a long time retard their civilization. As we see those animals, whose instinct compels them to live in society and obey a chief, are most capable of improvement, so is it with the races of mankind. Whether we look at it as a cause or a consequence, the more civilized always have the most artificial governments. (...) In Tierra del Fuego, until some chief shall arise with power sufficient to secure any acquired advantage, such as the domesticated animals, it seems scarcely possible that the political state of the country can be improved. At present, even a piece of cloth given to one is torn into shreds and distributed; and no one individual becomes richer than another. On the other hand, it is difficult to understand how a chief can arise till there is property of some sort by which he might manifest his superiority and increase his power." (Darwin, 1962: 230-231) ${ }^{27}$.

\footnotetext{
${ }^{27}$ A perfeita igualdade entre os indivíduos que compõem as tribos fueguinas, deve, por um longo tempo, retardar sua civilização. Como vemos que aqueles animais cujo instinto os compele a viver em sociedade e a obedecer seu chefe são mais capazes de aperfeiçoamento, assim o é com as raças de homem. Se olharmos a isto como causa ou como conseqüência, as mais civilizadas sempre possuem os governos mais artificiais. (...) Na Terra do Fogo, até que um chefe surja com poder suficiente para assegurar qualquer vantagem adquirida, tais como animais domésticos, parece quase impossível que o estado político do país possa ser
} 
"The Guasos of Chile, who correspond to the Gauchos of the Pampas, are, however, a very different set of beings. Chile is the more civilized of the two countries, and the inhabitants, in consequence, have lost much individual character. Gradations in rank are much more strongly marked: the Guaso does not by any means consider every man his equal; (...). This feeling of inequality is a necessary consequence of the existence of an aristocracy of wealth. (...)The Gaucho, although he may be a cut-throat, is a gentleman; the Guaso is in few respects better, but at the same time a vulgar, ordinary fellow." (Darwin, 1962: 260-1; Barlow, 1934: 239)28.

O sistema de relações que constitui as 'condições de vida' logo se revestirá, na teoria Darwiniana, do caráter de 'luta pela existência' - princípio e 'visão de Natureza'. Durante a viagem - e antes da leitura de Malthus -, em sua caderneta de anotações que o acompanhava em suas expedições, datada de 1833, já se pergunta acerca de 'taxas de nascimento e morte' de grupos de animais; no seu diário, em registro de sua estadia na Banda Oriental e Patagônia, Darwin chama a atenção para nossa ignorância das 'causas de extinção' e refere-se especialmente ao fato de que 'algum controle ao aumento da população está sempre em ação’ (Barlow, 1946: 175). Os traços de sua visão de Natureza como um sujeito dotado de uma dramaticidade, de um poder e de uma face própria, bem como seu preâmbulo a uma visão de Natureza como 'luta pela existência', também aparecem, no 'Retrospecto' das versões publicadas do seu diário, bem como em seu registro original de bordo. É uma visão de Natureza como 'luta de vida-e-morte', ao dizer que as cenas que mais o impressionaram, foram as dos poderes da vida das florestas brasileiras

aperfeiçoado. No presente, mesmo uma peça de roupa dada a um indivíduo é rasgada em trapos e distribuída; e nenhum indivíduo se torna mais rico do que outro. De outro lado, é difícil entender como um chefe pode surgir até que exista propriedade de algum tipo por meio da qual ele pudesse manifestar sua superioridade e aumentasse seu poder (Darwin, 1962: 230-231).

${ }^{28}$ Os guasos do Chile, que correspondem aos gaúchos dos Pampas, são, contudo, um grupo diferente de criaturas. O Chile é o mais civilizado dos dois países e os habitantes, conseqüentemente, perderam muito de seu caráter individual. As gradações de posições sociais são muito mais fortemente marcadas: o guaso de modo nenhum considera todo homem seu igual. (...) Este sentimento de desigualdade é uma conseqüência necessária da existência de uma aristocracia de riquezas. (...) O gaúcho, ainda que possa ser um 'cortador-de-garganta', é um 'gentleman'; o guaso é, em poucos aspectos, melhor, mas ao mesmo tempo um camarada vulgar, ordinário (Darwin, 1962: 260-1; Barlow, 1934: 239). 
e as dos poderes da morte das florestas da Terra do Fogo - 'ambas templos cheios das variadas produções do Deus da Natureza' (Darwin, 1962: 500). Mais tarde, em The Descent of Man (1871) Darwin se detém à aplicação da seleção natural para explicar o progresso civilizatório:

"At the present day civilised nations are everywhere supplanting barbarous nations, excepting where the climate opposes a deadly barrier; and they succeed mainly, though not exclusively, through their arts, which are the products of the intellect. It is, therefore, highly probable that with mankind the intellectual faculties have been gradually perfected through natural selection; and this conclusion is sufficient for our purpose. Undoubtedly it would have been very interesting to have traced the development of each separate faculty from the state in which it exists in the lower animals to that in which it exists in man; but neither my ability nor knowledge permit the attempt." (Darwin, 1871: 160) ${ }^{29}$.

Passagens como essa estão em muitas das associações feitas entre Darwin e o chamado 'Darwinismo Social' e a conseqüente lógica da dominação que nele encontraria justificativa. Contudo, essa se revela uma leitura pouca atenta e que descura outros pensamentos centrais de Darwin sobre o homem como um 'animal social'. Darwin ressalta em sua análise qualidades e habilidades intelectuais e morais, cuja origem encontra-se em sentimentos sociais básicos de simpatia e amor, resultantes em auxílio mútuo.

"At all times throughout the world tribes have supplanted other tribes; and as morality is one element in their success, the standard of morality and the number of well-endowed men will thus everywhere tend to rise and increase." (Darwin, 1871: 166) ${ }^{30}$.

${ }^{29}$ Nos dias de hoje, as nações civilizadas estão em todo o lugar suplantando as nações bárbaras, exceto onde o clima opõe uma barreira fatal: e elas são bem sucedidas principalmente, embora não exclusivamente, por meio das artes, que são produtos do intelecto. É, por conseqüência, altamente provável que, no caso do homem, as faculdades intelectuais tenham sido gradualmente aperfeiçoadas por meio da seleção natural; e essa conclusão é suficiente para nosso propósito. Sem dúvida, seria interessante traçar o desenvolvimento de cada faculdade em separado desde o estado em que existe nos animais inferiores até o que existe no homem; mas nem minha habilidade, nem o conhecimento permitiriam essa tentativa. (Darwin, 1871: 160).

${ }^{30}$ Em todos os tempos, no mundo inteiro, tribos suplantaram outras tribos: e como a moralidade é um elemento em seu sucesso, o padrão de moralidade e o número de indivíduos 
Diz-nos Darwin que pessoas egoístas e beligerantes não possuem coesão e que, sem coesão, nada pode ser realizado (Darwin, 1871: 162). E assim conclui: "Thus the social and moral qualities would tend slowly to advance and be diffused throughout the world" (Darwin, 1871: 163) ) $^{31}$ qualidades essas que igualmente caracterizam a espécie humana, tanto quanto características biológicas, e que estão entre os parâmetros para a avaliação do que seja bom para a espécie, parâmetro essencial para julgar o que seja bom para o indivíduo no caso dos animais sociais. A supremacia em questão revela-se, pois, uma supremacia que elevaria as capacidades intelectuais e morais do homem em suas habilidades e comportamento. Ainda que se argumente que tais capacidades e virtudes seriam aquelas assim entendidas pelo 'dominador', não esqueçamos que para Darwin elas não incluiriam a 'tirania' ou 'violência', ou 'extermínio', mas sim 'respeito', tendo exaltado a última e condenado as primeiras naquelas poucas passagens em que se detém no exame de fenômenos sociais, como o fez em sua viagem pela América do Sul. Para Darwin, conforme já mencionado, haveria um princípio ético comum, a soberania de um juízo responsável, com raízes em sentimentos sociais e desenvolvimento de capacidades intelectuais, que, em cada nação, estaria adaptado às circunstâncias próprias. Dada a influência de uma cultura sobre outra, como um colonista que se introduz em uma comunidade em equilíbrio, podemos acrescer que esse e outros mecanismos levam a constantes re-acomodações dos padrões de habilidade e comportamento.

A ação humana passa a interferir no que seria a rude ação da seleção natural. Todavia, o auxílio que damos ao desassistido não deixa de ser um resultado daquele sentimento de simpatia acumulado pela seleção natural. Nessa medida, passamos a ser um agente da seleção natural, a qual passa a se colocar em outro nível. Segundo Darwin, não poderíamos exercer controle (check) sobre nossa simpatia, se a razão a tanto nos exortasse, sem a deterioração da parte mais nobre de nossa natureza (Darwin, 1871: 169), sua instância ética. Algumas novas possibilidades são abertas para entender a ação da seleção natural no plano social:

talentosos em todo o lugar tenderá a surgir e a aumentar (Darwin, 1871: 166).

${ }^{31}$ Então, as qualidades sociais e morais tenderão a lentamente avançar e se difundirem por todo o mundo" (Darwin, 1871: 163). 
"Great lawgivers, the founders of beneficent religions, great philosophers and discoverers in science, aid the progress of mankind in a far higher degree by their works than by leaving a numerous progeny" (Darwin, 1871: 172) ${ }^{32}$.

Essa abertura a novas possibilidades abertas à seleção natural como condição explicativa para os fenômenos culturais e sociais, encontra sustentação à base da visão darwiniana de uma profunda integração entre o 'natural' e o 'cultural', em uma passagem que surpreende pela sua contemporaneidade em face de muito recentes abordagens dos estudos de mídia. Tome-se de um lado o cérebro, como representando o 'natural' e tome-se de outro a 'linguagem', que em seu exercício é 'cultural' e internalizada. Em suas considerações conclusivas ao final de Selection in Relation to Sex, Darwin diz:

"A great stride in the development of the intellect will have followed, as soon as, through a previous considerable advance, the half-art and halfinstinct of language came into use; for the continued use of language will have reacted on the brain, and produced an inherited effect; and this again will have reacted on the improvement of language" (Darwin, 1871: 390-391) ${ }^{33}$.

'Natural' e 'cultural' estão em constante interação na visão Darwiniana do homem, sem comprometê-la com "ismos" de qualquer espécie.

\section{Referências bibliográficas}

Barlow, N. 1993 [1958] (ed). The autobiography of Charles Darwin, 1809-1882: with original omissions restored. New York, W.W. Norton \& Co.

Darwin, C. 1958 [1892]. The autobiography of Charles Darwin and selected letters. Francis Darwin (ed.) New York, Dover Publications Inc.

${ }^{32}$ Grandes legisladores, os fundadores de religiões benéficas, grandes filósofos e descobridores na ciência, auxiliam o progresso da humanidade em um grau mais alto pelo seu trabalho do que por deixar uma prole numerosa (Darwin, 1871: 172).

${ }^{33} \mathrm{Um}$ grande avanço no desenvolvimento do intelecto terá seguido, logo que por meio de um avanço prévio considerável, metade pela arte e metade pelo instinto, a linguagem passou a ser usada; pois o contínuo uso da linguagem terá causado uma reação sobre o cérebro e produzido um efeito hereditário; e esse (efeito) novamente terá causado uma reação no aperfeiçoamento da linguagem (Darwin, 1871: 390-391). 
Darwin, C. 1934. The Beagle Diary 1831-1836. (edited by Nora Barlow). Cambridge, Cambridge University Press.

Darwin, C. 1987. Charles Darwin's Notebooks 1836-1845 (edited by Paul H. Barret et al.). Ithaca. Cornell University Press / British Museum (Natural History).

Darwin, C. 1985-2006. The correspondence of Charles Darwin. vol.1-vol.15 (edited by Burkhardt, F. et al.). Cambridge, Cambridge University Press.

volume 1 - 1822-1839 (1985)

volume $2-1837-1843(1986)$

volume $5-1851-1855$ (1989)

volume 6 - 1856-1857 (1990)

volume 7 - 1858-1859 \& Supplement to Correspondence 1821-1857 (1991)

volume $8-1860$ (1993a)

volume $9-1861$ (1994)

volume $12-1864(2001)$

volume $13-1865$ (2002)

volume $14-1866$ (2003)

Darwin, C. 1981 [1871]. The descent of man, and selection in relation to sex. Priceton, Princeton University Press.

Darwin, C. 1965 [1872]. The expression of the emotions in man and animals. Chicago, The University of Chicago Press.

Darwin, C. 1962 [1845]. The voyage of the Beagle (edited by Leonard Engel). New York, Doubleday and Company.

Darwin, C. 1946. Charles Darwin and the voyage of the Beagle, (edited, with an introduction, by Nora Barlow). New York, Philosophical Library.

Darwin, Francis (ed.) 1888. Life and letters of Charles Darwin, 3 vols. London, John Murray.

Darwin Correspondence Project, 2010. Darwin and Religion, Historical Essay. [Online] Cambridge, University of Cambridge [Consultado em 29/01/2010]. Disponível em: http://www.darwinproject.ac.uk/content/view/130/125/.

Darwin, C. 1980. Metaphysics, materialism, \& the evolution of mind (transcribed and annoted by Paul H.Barret). Chicago, University of Chicago Press.

Darwin,C. 1872. The origin of species by means of natural selection or the preservation of favored races in the struggle for life. London, John Murray.

Darwin, F.; Seward, A. C. (eds.) 1903. More letters of Charles Darwin. A record of his work in a series of hitherto unpublished letters. London, John Murray. Volume 1. 
Herschel, J. F. W. (1966) [1830]. A preliminary discourse on the study of natural philosophy. NewYork, Johnson Reprint Corporation (Introduction by Michael Partridge).

Hume, D. 2001 [1739-40]. Tratado da Natureza Humana. São Paulo, UNESP.

Manier, E. 1978. The Young Darwin and His Cultural Circle. Boston, D. Reidel Publishing Company.

Regner, A. C. K. P. 1988. Charles Darwin: Notas de Viagem - a tessitura social no pensamento de um naturalista. EST.

Artigo recebido a 22 de Fevereiro de 2010 e aceite a 14 de Julho de 2010. 